
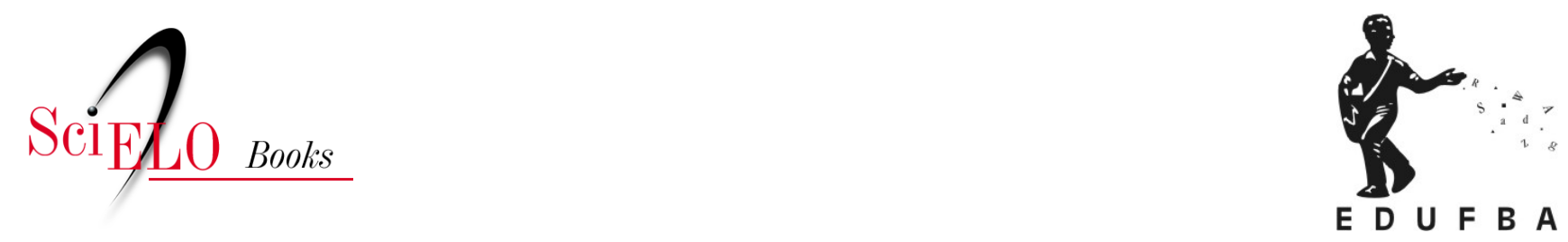

\title{
Politics \\ Políticas de saúde bucal no período pós-constituinte: governos FHC e Lula
}

\author{
Lucília Nunes Assis \\ Jairnilson Silva Paim \\ Catharina Leite Matos Soares
}

ASSIS, L.N., PAIM, J.S., and SOARES, C.L.M. Políticas de saúde bucal no período pós-constituinte: governos FHC e Lula. In: CHAVES, S.C.L. Política de saúde bucal no Brasil: teoria e prática [online]. Salvador: EDUFBA, 2016, pp. 117-136. ISBN 978-85-232-2029-7.

https://doi.org/10.7476/9788523220297.0005.

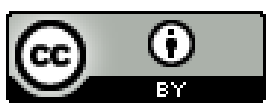

All the contents of this work, except where otherwise noted, is licensed under a Creative Commons Attribution 4.0 International license.

Todo o conteúdo deste trabalho, exceto quando houver ressalva, é publicado sob a licença Creative Commons Atribição 4.0. 


\section{Políticas de saúde bucal no período pós-constituinte \\ GOVERNOS FHC E LULA}

Lucília Nunes Assis

Jairnilson Silva Paim

Catharina Leite Matos Soares

Após a Constituição de 1988, a formulação e implementação das políticas de saúde bucal representaram um desafio semelhante ao da saúde em geral, onde os serviços de saúde bucal eram meros reprodutores do sistema nacional de saúde que refletia uma atenção centrada na assistência curativa, com nítida separação das ações de saúde pública, além dos gastos insuficientes na área e de sua má utilização. (MENDES, 1986)

Diante do quadro, o Sistema Único de Saúde (SUS), legalizado, poderia ser visto como uma possibilidade de proporcionar à saúde bucal, além de uma base doutrinária, diretrizes políticas favoráveis à expansão dos serviços, bem como a reorientação do modelo de atenção em saúde bucal centrado até então na atenção a escolares. A introdução da saúde bucal no Programa de Saúde da Família (PSF), por exemplo, além de buscar viabilizar maior cobertura dessa atenção e modificar o espaço de produção do cirurgião-dentista, poderia contribuir para a reordenação de sua prática. (RONCALLI, 2000)

Anos depois de promulgada a Constituição, Córdon(1991) apontava que a implementação do SUS alcançava êxito em experiências onde se aliava a vonta- 
de política local e a participação popular. Porém, salientava haver necessidade de maior controle social em relação aos aspectos financeiros e na própria organização das práticas de saúde. Afirmava que as políticas de saúde bucal guardavam traços de centralismo, onde o monopólio do conhecimento refletia-se na tomada de decisões sobre o trabalho sem o envolvimento da comunidade, fato que comprometia a legitimidade dessas políticas e a manutenção dos serviços que se organizavam, ao haver mudança dos atores políticos locais.

A partir de 2000 , fatos importantes foram produzidos no cenário da saúde nacional na área da saúde bucal, tais como a entrada da saúde bucal na Estratégia de Saúde da Família e a formulação da Política Nacional de Saúde Bucal (PNSB). (BRASIL, 2000; 2004)

Dada a relevância de se compreender esse contexto, pretendeu-se assim, uma análise das políticas de saúde bucal, buscando reunir informações com a intenção de apreender a totalidade que a questão encerra (BRUYNE et al., 1997), tomando o período pós-constituinte como objeto de reflexão, por ser considerado um momento histórico significativo, rico em relações de forças estabelecidas entre diversos atores sociais que constituem o campo da Saúde Coletiva. Buscou-se realizar uma abordagem histórica e estrutural para o estudo de políticas de saúde bucal formuladas, na conjuntura pós-constituinte, particularmente nos governos de Fernando Henrique Cardoso (FHC) (19992002) e Luís Inácio Lula da Silva (2003-2004) a fim de identificar e analisar fatos políticos produzidos nesses governos no que tange a saúde bucal.

\section{Elementos teóricos}

Os fatos políticos a serem considerados tomam, de forma mais abrangente, a denominação de políticas públicas, de onde se esquadrinha os propósitos de governo em relação às políticas de saúde bucal. (TESTA, 1992) Assim, considerou-se um Estado capitalista periférico que produz políticas públicas, particularmente na área da saúde, respondendo a necessidades variadas, sendo as políticas de saúde respostas ou não a demandas diversas, tais como aquelas referentes aos problemas do estado de saúde e do sistema de saúde; relativas a determinantes econômicos (reprodução e manutenção da força de trabalho, produção de bens e serviços, entre outros) e, ainda, respostas a determinações de cunho político-ideológico para a coesão de todo o conjunto. (FERREIRA, 1990; PAIM, 2003) Coesão complexa, cujas respostas consentidas perpassam pelo aparelho do Estado, imbricado de interesses públicos legítimos e particu- 
lares, corporativos e partidários. Tal enfoque, acima descrito, permite a análise das políticas sociais em um plano estrutural, considerando as determinações oriundas do Estado capitalista. Essas políticas, portanto, no âmbito de um Estado ampliado, são respostas seletivas às demandas de múltiplos sujeitos coletivos. (COUTINHO, 1995) Ao se considerar a singularidade das políticas de saúde, pode-se, ainda, aperfeiçoar tal plano de análise, tomando como referência as instituições por onde se vocalizam os interesses dos grupos diversos. Nesse aspecto, além das demandas a serem consideradas, as respostas dadas são condizentes com estratégias políticas utilizadas pelas instituições para responder problemas de dominação, específicos do aparelho estatal, além de considerar questões administrativas, orçamentárias e os próprios conflitos sociais advindos das leis e regulamentos. (GERSCHMAN, 1995; OFFE, 1989)

No contexto descrito, faz-se necessária uma análise da conjuntura composta pelos distintos governos onde se formulam as políticas de saúde bucal. Conjuntura compreendida enquanto "um feixe de relações contraditórias (relações de força) que implica o conhecimento do desenvolvimento desigual dessas relações em cada um dos níveis que articuladamente compõem a totalidade social" (GRAMSCI, 1980, p. 48), estando, tais relações, refletidas no sistema de representação de interesses diversos e nas suas consequências sobre as políticas de saúde. (TEIXEIRA, 1995) Por fim, entende-se que as políticas de saúde bucal representam um recorte das políticas de saúde, de modo que o estudo toma como objeto a análise dessas políticas enquanto expressão dos propósitos de governo, considerando a conjuntura em que se dá a sua formulação. (TESTA, 1992)

Cabe também destaque a reflexão sobre o Estado, enquanto uma totalidade orgânica com a sociedade civil, onde a classe dirigente, através de um complexo de práticas e teorias, justifica seu domínio e obtém a reprodução social com o consentimento dos governados, representando uma condensação material de uma relação de forças contraditórias e caracterizando-se como um campo de influências das mesmas. (GRAMSCI, 1980; POULANTZAS, 1980) Esse agrupamento tem como destino criar condições de expansão, sendo as conquistas decorrentes vistas como universais, desenvolvendo-se através de equilíbrios instáveis entre os interesses dos grupos dominados e o dominante. Assim, Gramsci considera hegemonia como direção e controle que uma classe ou fração de classe exerce sobre a totalidade da sociedade mediante a coerção 
ou o consenso. A ideologia de classe ou fração de classe dominante passa a ser a de toda a sociedade. (GRAMSCI, 1980)

Para a produção desses fatos políticos, partiu-se basicamente da análise de textos oficiais, tais como leis, projetos de lei, normas, portarias, decretos, medidas provisórias, manuais e relatórios, alusivos à atenção à saúde bucal, tomando-se como referência os momentos do ciclo da política, particularmente a formação da agenda, a formulação e a implementação (CPPS/OPS, 1975), bem como os distintos componentes de um sistema de serviços de saúde: gestão, financiamento, organização da atenção, infraestrutura e modelo de atenção. (KLECZKOWSKI; ROEMER; WERFF, 1984; PAIM, 2003) Entre os componentes do sistema de saúde, entende-se por "infraestrutura" os recursos essenciais para o funcionamento do sistema de saúde, envolvendo os trabalhadores da saúde, estabelecimentos, medicamentos, equipamentos e outros insumos. Entende-se por "organização" a conformação dos variados recursos nos serviços de saúde, considerando aspectos relativos à estrutura física, a materiais, insumos e recursos humanos. A "gestão" se refere à prática político-administrativa que objetiva a implementação das políticas, fazendo uso de tecnologias desenvolvidas no campo da administração. O componente "modelo de atenção" refere-se especificamente à dimensão técnica das práticas de saúde, ou seja, à lógica que orienta como as combinações tecnológicas são aplicadas na intervenção de problemas e necessidades de saúde, individuais ou coletivas. O "financiamento" da saúde engloba as fontes das três esferas governamentais e suas respectivas aplicações em ações e serviços de saúde, recursos físicos e humanos. Caracteriza-se pela forma de ordenação, repasse dos incentivos, bem como, a prioridade de alocação, tendo-se em perspectiva o efeito produzido, nesse campo, pelas políticas macroeconômicas. (MUSGROVE, 2001)

\section{O governo FHC}

O governo FHC, no seu segundo mandato, desencadeou um conjunto de iniciativas no âmbito da saúde bucal, sob a liderança do ministro José Serra. A partir do ano 2000, o termo de compromisso pactuado entre gestores dos três níveis de governo, passou a incluir indicadores referentes às ações de odontologia na atenção básica. Também nesse ano, destacado pela vinculação das receitas das três esferas de governo com os gastos em saúde, segundo a Emenda Constitucional n. ${ }^{\circ}$ 29, definiram-se repasses próprios para a saúde bucal no SUS, com a implantação de incentivos no Piso da Atenção Básica, para muni- 
cípios que desenvolvessem ações de saúde bucal através das Equipes de Saúde Bucal (ESB) implantadas no PSF. (ASSIS, 2006)

A Portaria GM/MS n. ${ }^{\circ}$ 1.444/2000 estabeleceu que cada ESB deveria atender, no mínimo, 6.900 habitantes e, para cada ESB implantada, haveria a correspondência de duas Equipes de Saúde da Família (ESF), sendo que, nos municípios com menos de 6.900 habitantes, a relação poderia ser na proporção de uma ESB para uma ESF. Nessa portaria, ficou definido que o incentivo financeiro seria repassado aos municípios qualificados, fundo a fundo, em parcelas mensais (1/12), de acordo com a modalidade de ESB implantada. Além do incentivo para o custeio das ações e inserção dos profissionais, criou-se também, com essa legislação, o incentivo adicional por equipe implantada, para aquisição de instrumental e equipamentos odontológicos. Previa-se que a incorporação dessas equipes consideraria a adequação de espaços para a reestruturação dos serviços odontológicos, a partir das instalações já existentes e as iniciativas locais de organização dos serviços, cabendo ao gestor municipal garantir a infraestrutura e os equipamentos necessários para o desenvolvimento das ações específicas.

As orientações para a reorganização das ações e serviços de saúde bucal previstas na Portaria GM/MS n. ${ }^{\circ}$ 267/2001, após a criação do incentivo para a inserção da saúde bucal no PSF, também definia o papel a ser desempenhado pelos profissionais da área, cabendo-lhes a responsabilidade sanitária em relação à população adscrita, com o desenvolvimento de ações de prevenção de doenças e agravos, além de promoção e recuperação da saúde. Ampliava-se, assim, o campo de ação da ESB, atribuindo-se a todos os seus profissionais atividades de planejamento, monitoramento e avaliação das ações desenvolvidas pela ESF; identificação das necessidades de saúde bucal da população adscrita; estímulo e realização de atividades educativas, de promoção e proteção em saúde bucal; organização do processo de trabalho segundo diretrizes do PSF e Plano Municipal de Saúde; programação e realização de visitas domiciliares de acordo com as necessidades identificadas e desenvolvimento das ações intersetoriais para a promoção da saúde bucal. Detalharam-se, ainda, as atribuições específicas do Cirurgião-Dentista (CD), Técnico em Higiene Dental (THD), Atendente em Consultório Dentário (ACD) e do próprio Agente Comunitário de Saúde (ACS). No que tange às ações de prevenção de doenças e agravos, consta que a ESB também ficaria responsável pela realização de ações básicas de vigilância epidemiológica. Tal atividade podia se operacionalizar a partir de 
um registro no Sistema de Informação Ambulatorial (SIA) do SUS, que incluía a categoria do CD no desenvolvimento de ações educativas em grupo sobre vigilância da saúde.

No final da vigência da Norma Operacional Básica - SUS o1/96 (NOB-SUS 01/96), permanecia como desafio as limitações da capacidade de planejamento e coordenação das Secretarias Estaduais de Saúde, o que favoreceu o isolamento dos sistemas municipais e a incorporação tecnológica irracional, dificultando a estruturação de uma rede regionalizada, hierarquizada e resolutiva. (BRASIL, 1996) Frente a esses problemas, o desenvolvimento de ações especializadas na área passou a se associar à habilitação segundo Normas Operacionais da Assistência à Saúde, com a elaboração do Plano Diretor de Regionalização (PDR) e definição de microrregiões que deveriam desenvolver um conjunto de procedimentos de média complexidade, como primeiro nível de referência intermunicipal, organizados em um ou mais módulos assistenciais. (BRASIL, 2002a)

Concomitante à implementação das ESBs no PSF, definiram-se ações e estratégias mínimas como a prevenção de problemas odontológicos, realização de consultas e procedimentos clínicos ambulatoriais. Além das ações básicas, abordou-se a oferta de ações especializadas, identificando aquelas que deveriam estar incluídas no rol da atenção básica ampliada e definiu-se um elenco de procedimentos da média complexidade a serem ofertados por municípiossede. Dentre eles, citam-se tratamento e retratamento endodôntico de dentes permanentes e decíduos, radiografias periapical e interproximal. Quanto à oferta organizada das ações e procedimentos por nível de atenção, coube ao gestor municipal definir o fluxo de referência e contrarreferência para serviços de maior complexidade ou de apoio diagnóstico, considerando o PDR. Assim, a gestão estadual tinha como responsabilidade a inclusão das ações de saúde bucal em tal plano. (ASSIS, 2006)

A operacionalização dos serviços de referência odontológica pelos municípios habilitados, segundo Norma Operacional de Assistência à Saúde (NOAS), apoiou-se na discriminação disposta pelo Ministério da Saúde (MS) de cada equipamento necessário para a execução de tais procedimentos, incluindo a cobertura populacional prevista para o caso de aparelhos diagnósticos. (BRASIL, 2002a) O número de consultórios odontológicos e de CDs também passou a fazer parte dos critérios para a avaliação da atenção básica dos municípios que pleiteassem essa condição de gestão, bem como o registro de produção 
no SIA/SUS. Tal avaliação era feita através de marcadores específicos, como a cobertura de procedimentos coletivos e primeiras consultas odontológicas. (ASSIS, 2006)

Em 2002, o Encontro Nacional de Administradores e Técnicos do Serviço Público Odontológico (Enatespo) chamava a atenção para a difícil implementação dos serviços de média complexidade, discriminados nas NOAS, no que tange à saúde bucal, afirmando-se, que devido ao alto custo dos procedimentos de radiologia e endodontia, dificilmente eles seriam assimilados pelos municípios, mesmo porque a tabela do SIA/SUS não favorecia aos prestadores e, no caso dos municípios não habilitados em tal norma, a oferta de tais serviços à população dependia de sua inserção pelos gestores na programação físico-orçamentária da saúde, sem previsão de recursos federais.

Apesar do avanço do discurso institucional no que tange à área técnica em saúde bucal, as NOAS mantiveram a orientação de organização dos serviços em saúde bucal voltados para a faixa etária de $\circ$ a 14 anos em relação aos procedimentos preventivos e coletivos, além dos restauradores. Recomendava-se, também, a inclusão de consultas não agendadas para o cumprimento do atendimento das urgências odontológicas, sem especificar faixas etárias prioritárias. (BRASIL, 2002a) Por sua vez, o XVI Enatespo, na época, já apontava que a inserção da saúde bucal no PSF deveria prever uma abordagem universal de ações promotoras e preventivas, tendo como retaguarda o acesso irrestrito à atenção curativa. Tal evento propunha ainda que, nas regiões com infraestrutura relativa à rede de abastecimento público, fosse obrigatória a fluoretação das águas, como um pré-requisito para a implantação das ESBs. Em relação ao tema flúor, vale destacar que a $11^{\text {a }}$ Conferência Nacional de Saúde (CNS) e o XVII Enatespo reiteram dentre suas propostas a importância da fiscalização da água de abastecimento e das pastas de dente pela vigilância sanitária, por estas serem os produtos fluoretados de maior consumo no país, além de propor a definição de normas para aplicação tópica do flúor.

Esses dois últimos eventos citados reconheciam a existência no país de um modelo de atenção inadequado, com manutenção do caráter assistencialista, obsoleto, curativista, centrado na figura do médico, havendo necessidade, inclusive, de reconstrução das relações de poder nas equipes de saúde. Discutia-se a necessidade de uma maior interlocução entre usuários e profissionais da ESB, e propunha-se que a oferta de ações e serviços considerasse o espaço social e a necessidade percebida como ferramentas orientadoras da programação, além de 
construir um modelo integral de atenção que priorizasse grupos mais vulneráveis, ao invés da oferta de serviços segundo demanda livre. (ASSIS, 2006)

Dentre as propostas emanadas de eventos como conferências de saúde e Enatespo, no período do segundo mandato do governo FHC, no que tange ao controle social, tem-se reivindicações relativas à necessidade de participação popular mais efetiva através de conselhos de saúde mais representativos e deliberativos, bem como facilitação da mobilização social e educação pela comunicação entre setor saúde e população, incluindo o repasse de informações sobre dados relativos à situação de saúde, além daqueles pertinentes aos recursos financeiros e humanos disponíveis. (ASSIS, 2006)

Em se tratando dos Recursos Humanos (RH) em Saúde Bucal, tomando como referência proposições dos Enatespos posteriores a 1999, observa-se a similaridade do discurso em prol da garantia de inserção da ESB na equipe mínima do PSF, em uma referência direta à sua composição pelo médico, enfermeiro, auxiliar de enfermagem e ACS, desde 1997. Faz-se constar que, no XVII Enatespo, o tema é tratado com ressalvas, onde se ponderou que a inserção das ESBs no PSF de forma normativa e em rápida expansão, sem uma ampla discussão, principalmente sobre questões referentes ao modelo de atenção, poderia representar uma ameaça à própria proposta da saúde bucal no âmbito do programa. Daí, esse evento enfatizar a retomada do Movimento de Reforma Sanitária no âmbito da odontologia, através das entidades de categoria e estudantes da área. O tema da intersetorialidade permeia o conteúdo desses eventos de forma geral, sejam aqueles pertinentes especificamente à saúde bucal ou não, no que se refere à saúde e sua relação com os aspectos das políticas econômicas, educacionais, alimentares, do trabalhador, da população privada de liberdade, da criança e do adolescente, do índio, entre outras. (ASSIS, 2006)

No segundo mandato do governo FHC, fatos institucionais relativos a uma política específica de grupo apresentou maior correspondência com propostas da $11^{\mathrm{a}} \mathrm{CNS}$. Trata-se do programa do presidiário que se institui em 2002. (BRASIL, 2002b) Nesse plano, estabelecia-se que 70\% do custo das ações a serem desempenhadas ficariam a custo do MS e os $30 \%$ restantes caberiam ao Ministério da Justiça. Tal compromisso de incentivo ficou corroborado por termo de compromisso devidamente aprovado pelos dois ministérios, prevendo-se a contrapartida das Secretarias Estaduais de Saúde e de Justiça. O plano previa o atendimento por uma equipe mínima de saúde, incluindo médico, enfermeiro, auxiliar de enfermagem, odontólogo, ACD, assistente social e psicólogo. Assim, 
cada população de 500 presos teria a cobertura de uma equipe. No mesmo ano de instituição do plano, houve repasse de recursos para os estados habilitados desenvolverem o programa. (BRASIL, 2002b)

Ainda no que se refere a programas especiais, limitados a políticas setoriais voltadas para grupos específicos, tem-se ações relativas à saúde bucal no programa da saúde indígena. Destaca-se que, em 1999, a Fundação Nacional de Saúde (Funasa) reassumiu a responsabilidade pela assistência médico-sanitária aos índios, anteriormente fragmentada entre esta instituição, responsável apenas por ações de prevenção (imunização, saneamento, controle de endemias etc.), e a Fundação Nacional do Índio (Funai), então prestadora das ações curativas. Posteriormente, ressaltou-se a necessária articulação entre Funasa e Secretaria de Assistência à Saúde/MS para execução das ações de atenção à saúde dos povos indígenas, com observação dos princípios e diretrizes do SUS. $\mathrm{Na}$ atenção básica, esses recursos destinavam-se ao apoio da implantação de equipes multidisciplinares com inclusão do cirurgião-dentista. (ASSIS, 2006)

\section{O governo Lula}

Os primeiros anos do governo Lula apresentaram vários fatos institucionais que demonstraram um claro propósito de expansão da atenção à saúde bucal no SUS. Já em abril de 2003, o MS reajustou os valores dos incentivos financeiros relativos à atenção básica, incluindo aqueles pertinentes às ações de saúde bucal, no âmbito do PSF. Posteriormente, estabeleceu-se que se poderiam instalar nos municípios quantas ESB fossem necessárias, a critério do gestor municipal, desde que não ultrapassem o número existente de ESF, e se mantivesse em coerência com a lógica de organização da atenção básica. Reiterou-se, na mesma ocasião, a manutenção dos incentivos de custeio e implantação das ESBs, sendo requisitos para o recebimento dos recursos a qualificação dos municípios na Comissão Intergestora Bipartite e a alimentação mensal do Sistema de Informação Ambulatorial da Atenção Básica, com informação do número das ESBs em atuação, as ações desenvolvidas a as respectivas modalidades. Essas informações é que possibilitariam o cálculo dos incentivos a serem repassados na implantação de uma nova equipe. (ASSIS, 2006)

Seis meses após a viabilização da equiparação entre ESB e ESF, ocorreu novo reajuste dos incentivos da saúde bucal na atenção básica, orientando-se que, na compra dos materiais clínicos permanentes, deveriam estar incluídos aqueles utilizados para a confecção de próteses, fato que encontra correspon- 
dência com a inclusão de um procedimento no grupo das ações de atenção básica em odontologia do SIA, no subgrupo de reabilitação oral. (ASSIS, 2006)

Houve mudanças na forma de repasses de recursos para o financiamento da atenção básica, sendo incluídos como critérios a existência de desigualdades expressas nos indicadores epidemiológicos, nas dificuldades de retenção de profissionais e na dificuldade de acesso da população. Assim, proporcionou-se um aumento de 50\% aos incentivos do PSF e saúde bucal nos municípios com Índice de Desenvolvimento Humano (IDH) igual ou inferior a 0,7, com população de até 50 mil habitantes; nos estados da Amazônia Legal, incluindo, também, aqueles até 30 mil habitantes nos demais estados do país. Além disso, o mesmo se aplicou para os municípios com populações remanescentes de quilombos, residentes em assentamentos, com 70 ou mais pessoas. (ASSIS, 2006)

No segundo ano de governo do presidente Luiz Inácio Lula da Silva, foi lançado um programa nacional exclusivo para a saúde bucal, denominado Brasil Sorridente. Em documento que tratou das diretrizes políticas que englobam esse programa, referenciou-se que elas resultavam de um amplo processo de discussão, envolvendo coordenadores estaduais de saúde bucal, além de se fundamentar em proposições oriundas de conferências, encontros de odontologia e de saúde coletiva, fato amplamente verificado através dos relatórios divulgados por estes eventos mais recentes. (BRASIL, 2004a)

De forma geral, o documento apresentou pressupostos para a reorientação do modelo de atenção em saúde bucal, fundamentados nos princípios e diretrizes do SUS, segundo legislação vigente. Assumiu o PSF como grande oportunidade de reorientação do processo de trabalho na saúde bucal, destacando ações que tornariam a atenção básica mais resolutiva e para a operacionalização da assistência integral, determinou-se a implantação pelo MS de serviços de referência especializada em odontologia. Estes tiveram a sua institucionalização e implementação a partir de setembro de 2004, através dos Centros de Especialidades Odontológicas (CEO) e Laboratórios Regionais de Próteses Dentárias (LRPD). Dessa forma, a operacionalização desses serviços de referência associou-se a repasses federais na forma de incentivos de custeio e implantação, no caso dos CEOs, ou por pagamento segundo produção, no caso dos LRPDs. Assim, foram necessários acréscimos de procedimentos no SIA/SUS a serem realizados pelo Técnico em Prótese Dental (TPD), bem como, a inclusão da categoria profissional do CD patologista bucal e respectivos procedimentos. Recomendava-se que a organização desses serviços de referência, 
principalmente no que tange aos CEOs, considerasse para cobertura populacional o PDR. (ASSIS, 2006)

Segundo o MS, até 2003 , apenas 3,3\% dos atendimentos odontológicos feitos no SUS correspondiam a tratamentos especializados. O grande diferencial dessa política de saúde bucal, em relação às anteriores, portanto, centra-se no investimento para a organização de serviços públicos especializados em odontologia. Porém, em se tratando dessa recente implantação de serviços de referência, vale ressaltar que a $12^{\mathrm{a}}$ CNS e $3^{\mathrm{a}}$ Conferência Nacional de Saúde Bucal (CNSB) abordaram a importância da organização dos mesmos através de centrais de regulação. (BRASIL, 2003)

De forma geral, o conjunto de diretrizes apresentadas em eventos como a $12^{\mathrm{a}}$ CNS e $3^{\mathrm{a}} \mathrm{CNSB}$, referentes à orientação do modelo de atenção em saúde bucal, encontrou consonância nas Diretrizes da PNSB, em 2004. Assim, o conteúdo dessas proposições apresenta a recomendação da ampliação do acesso e a superação do modelo biomédico de atenção às doenças bucais, a partir de ações programáticas por linha de atenção, baseadas nas especificidades da faixa etária - criança, adolescente, adulto, idoso e por condição de vida -, saúde da mulher, saúde do trabalhador, saúde de portadores de necessidades especiais, hipertensos, diabéticos, entre outras. Rompe-se com o discurso de priorização da faixa etária de o a 14 anos para uma abordagem universal, sem fazer distinção entre grupos e respectivas ações a serem priorizadas. Essa universalidade da atenção, por sua vez, associa-se com a recomendação de que o deslocamento do CD, para o desenvolvimento das ações de saúde coletiva, seja criterioso, cabendo o exercício dessas atividades ao demais integrantes da ESB e ACS. Tal orientação pressupunha uma autonomia desses sujeitos e uma adequada programação dos serviços, incluindo processos de supervisão e avaliação, tendo no CD, o papel de coordenador. (ASSIS, 2006)

Essas diretrizes políticas estabelecidas no governo Lula, em 2004, também previam a realização de diagnóstico em saúde bucal o mais precocemente possível com o tratamento que priorizasse procedimentos conservadores, entendidos como todos aqueles executados para manutenção dos elementos dentários, invertendo a lógica que leva à mutilação, considerada então predominante nos serviços públicos. (BRASIL, 2004) Tais propostas relativas ao processo de trabalho em saúde bucal encontram correspondência com a situação encontrada em 2003 , onde os principais problemas da população brasileira em saúde bucal 
apresentaram-se como cáries não tratadas em crianças e jovens e perda dentária em adultos e idosos.

Cabe destacar que a $12^{\mathrm{a}}$ CNS reiterou todas as preconizações, disponibilizadas pelo MS em 2004, no que tange à dosagem adequada e monitoramento do flúor em águas de abastecimento, ressaltando que a questão era uma responsabilidade intersetorial do SUS. Por sua vez, essa conferência cobrou a garantia de implementação de uma Agenda Nacional de Prioridades de Pesquisa em Saúde que incluísse, dentre os seus temas, a fluorose, fazendo referência específica a estudos que abordassem a relação entre cremes dentais infantis e casos da doença. Já a $3^{\text {a }}$ CNSB, além da garantia da fluoretação das águas de abastecimento, propôs a criação de uma política de incentivo para a produção de insumos para higiene oral, materiais e produtos odontológicos, frente a uma ação reguladora da Agência Nacional de Vigilância Sanitária em relação a produtos que possam causar problemas de saúde bucal em geral, como chupetas, mamadeiras, escovas de cerdas duras etc. Esses temas, em geral, encontraram relação com as proposições da política Brasil Sorridente a partir da definição de critérios para a aplicação tópica de flúor de forma criteriosa pelos profissionais, além da expansão das águas de abastecimento fluoretadas com articulação entre Funasa, MS e Secretarias Estaduais de Saúde, bem como a previsão de distribuição de 1,9 milhões de kits de higiene oral, anualmente, entre 2004 e 2007. (ASSIS, 2006)

A proposta de definição de uma política de humanização pela $12^{a}$ CNS encontrou ressonância com o discurso da Política Nacional de Humanização do SUS, em janeiro de 2004 (BRASIL, 2004b) As diretrizes para sua operacionalização referiam-se ao direito do usuário de saber quais são os profissionais que o atendem, possibilitando o vínculo e corresponsabilidade; redução de fila com acolhimento, avaliação de risco e priorização para atendimento; além de ações voltadas para a maior participação dos usuários e profissionais na gestão dos serviços dessa saúde. (KLECZKOWSKI; ROEMER; WERFF, 1984) Assim, essa política recomenda a implementação dessas diretrizes nos planos de saúde dos diferentes níveis governamentais, visando articulação de recursos e compromissos com a humanização do SUS. (ASSIS, 2006)

Sobre questões relativas à formação dos recursos humanos em saúde bucal, a $3^{\text {a }}$ CNSB, em 2004, apontava o crescimento de $100 \%$ dos cursos de graduação de odontologia apenas em uma década, totalizando 161 cursos, em sua maioria, particulares e concentrados nas regiões mais desenvolvidas do país. Tal Conferência declarava que o sistema de ensino superior não estava cumprindo seu 
papel formador de RH comprometido com o SUS e com o controle social, nem considerando as reais necessidades de saúde bucal da população brasileira. Um dos entraves apontados referia-se à falta de articulação entre a saúde e a educação, com autonomização das universidades públicas e privadas. Por fim, abordou-se a permanência da pós-graduação com ênfase em especializações que confirmavam o caráter mercantilista e elitista da odontologia no Brasil, mantenedora do mesmo marco pedagógico conceitual da graduação. (ASSIS, 2006)

Ainda se tratando de RH em saúde bucal, tem-se a dificuldade de interiorização do profissional odontólogo, fato abordado na $3^{\mathrm{a}} \mathrm{CNSB}$, que fez referência à necessidade de incentivos para a fixação dos profissionais no interior através do Programa de Interiorização do Trabalho em Saúde, instituído em 2001, que, mesmo após a inclusão da ESB no PSF, permanece, no período analisado, incluindo somente as categorias de médicos e enfermeiros. Em relação à remuneração dos CDs, uma recomendação recorrente em eventos da área, é a isonomia salarial da categoria à dos médicos. (ASSIS, 2006)

No governo Lula, dentre as políticas relativas a programas voltados para grupos específicos que apresentaram maior correspondência com a saúde bucal, destaca-se a política para os privados de liberdade, através da reinstituição do Plano Nacional de Saúde do Sistema Presidiário em 2003. Manteve-se assim o financiamento intersetorial, aumentando-se a cobertura de 501 a 1.000 presidiários por duas equipes mínimas, com carga horária de 20 horas semanais por profissional, além da garantia da atenção à saúde bucal básica segundo cobertura disposta na NOAS-SUS 01/2002. Houve ainda a criação do cargo de agente promotor de saúde, um por equipe, a ser ocupado por presidiário selecionado. No caso de municípios com população prisional até 100 indivíduos, a rede local passa a assumir a responsabilidade pela oferta de ações e serviços da atenção primária, mediante repasse de incentivo específico ao município. (ASSIS, 2006)

\section{A política de saúde bucal e o acúmulo histórico dos fatos institucionais}

A análise dos dois governos revelou que houve avanço na formulação e implementação de ações para a área de saúde bucal, desde propostas na atenção primária com a inserção da atenção odontológica no PSF no governo FHC até a formulação de uma política específica para esse setor no governo Lula. O Quadro 1 sistematiza os principais fatos produzidos na atenção à saúde bucal nos dois governos (FHC e Lula I). Observou-se incorporação das principais proposições dos movimentos da área - Enatespo e CNSB - nas políticas formuladas, 
apontando para uma resposta social do Estado às necessidades de saúde de grupos organizados específicos, que, teoricamente, expressam o caráter coletivo dessas reinvindicações. Contudo, há evidências do caráter secundário dessa política, como também revelou Vianna (1988) em períodos anteriores.

Quanto aos componentes do sistema de saúde (gestão, financiamento, organização e infraestrutura, modelo de atenção), observou-se uma maior ênfase no aspecto organizacional e de infraestrutura, mas pouca clareza quanto ao modelo de atenção e financiamento do sistema, especialmente no governo FHC. (ASSIS, 2006)

\section{Quadro 1 - Principais fatos políticos produzidos no âmbito de saúde bucal nos governos FHC (1995-2002) e Lula (2003-2006) quanto aos cinco componentes dos sistemas de saúde \\ (continua)}

\begin{tabular}{|c|c|}
\hline Governos & Fatos políticos produzidos \\
\hline $\begin{array}{c}\text { FHC } \\
(1995-2002)\end{array}$ & $\begin{array}{l}\text { Financiamento } \\
\text { Criação de incentivos específicos para ESB no PSF. } \\
\text { Organização e infraestrutura } \\
\text { Orientações sobre a organização da atenção em saúde bucal (NOAS). } \\
\text { Definição de procedimentos de média complexidade em saúde bucal, segundo } \\
\text { habilitação (NOAS). } \\
\text { Gestão } \\
\text { NOB SUS 01/96 não se refere à saúde bucal. Manual da reorganização da } \\
\text { atenção básica referindo a ações em odontologia e cria indicador em saúde } \\
\text { bucal. Presença de consultórios odontológicos é condicional em unidades de } \\
\text { atenção básica e mista. Inserção da ESB no PSF. } \\
\text { Inclusão do indicador em saúde bucal no compromisso do pacto para a } \\
\text { atenção básica. } \\
\text { NOAS atrela o desenvolvimento de ações em saúde bucal como critério para } \\
\text { habilitação. } \\
\text { Presença de dentista, consultório odontológico e produção no SIA passam a } \\
\text { ser critérios para habilitação. } \\
\text { Modelo de Atenção } \\
\text { Realização de levantamento epidemiológico em escolares de capitais brasileiras. } \\
\text { Edição das Normas e Diretrizes da Saúde Bucal no PSF. Manual da Reorientação } \\
\text { da Saúde Bucal na atenção básica descreve atribuições e responsabilidades do } \\
\text { CD, THD, ACD e ACS. Ampliação do campo de ação da ESB no PSF. Programa } \\
\text { do Presidiário é lançado e instituído. }\end{array}$ \\
\hline
\end{tabular}


Quadro 1 - Principais fatos políticos produzidos no âmbito de saúde bucal nos governos FHC (1995-2002) e Lula (2003-2006) quanto aos cinco componentes dos sistemas de saúde

(conclusão)

\begin{tabular}{|c|c|}
\hline $\begin{array}{c}\text { Lula } \\
(2003-2006)\end{array}$ & $\begin{array}{l}\text { Financiamento } \\
\text { Ampliação de incentivo para implantação proporcional entre ESBs e ESFs. } \\
\text { Criação e manutenção de uma ação orçamentária específica para a saúde bucal } \\
\text { (2004); o reajuste de } 20 \% \text { no valor do incentivo de implantação repassado } \\
\text { para as ESB (2004); a determinação do financiamento para o CEO e próteses } \\
\text { dentárias (2004), segundo tetos, por produção. Aumento do incentivo em } \\
\text { saúde bucal para municípios com baixo IDH. } \\
\text { Organização e infraestrutura } \\
\text { Em 2006, o governo chegou a } 15.086 \text { ESBs (254,04\% de aumento em relação } \\
\text { a 2002). } \\
\text { Oferta de serviços especializados em } 2004 \text { com 100 centros especializados e } \\
\text { no final do governo chega a } 498 \text { centros (aumento de 398\%). } \\
\text { Gestão } \\
\text { Lançamento do Brasil Sorridente. Institucionalização de LRPDs. Implantação de } \\
\text { CEOs tipo I e tipo II. Inclusão de procedimentos do THD no SIA e da categoria } \\
\text { TPD e CD patologista bucal. Publicação da portaria que determina o valor } \\
\text { máximo permitido de fluoreto por mg/L de água (2004); a criação do Comitê } \\
\text { Técnico Assessor para estruturação (Comitê Tecnico Assessor - Vigilância em } \\
\text { Saúde Bucal - CTA-VSB e implantação da estratégia de vigilância em saúde } \\
\text { bucal dentro da PNSB); a determinação de critérios, normas e requisitos para } \\
\text { implantação e habilitação dos CEOs e LRPDs (2004). } \\
\text { Modelo de Atenção } \\
\text { Conclusão de levantamento epidemiológico em saúde bucal SB2000, em nível } \\
\text { nacional. } \\
\text { Diretrizes de Política Nacional com ações programáticas por linha de atenção. } \\
\text { Aumento do incentivo em saúde bucal para municípios com baixo IDH . } \\
\text { Definição do perfil de competências do THD e ACD. Definição de critérios para } \\
\text { a aplicação tópica de flúor. } \\
\text { Distribuição de kits de higiene oral. Ampliação da cobertura dos presidiários } \\
\text { por equipes de saúde. Definição do perfil de competências do THD e ACD. }\end{array}$ \\
\hline
\end{tabular}

Fonte: Documentos-Base do Ministério da Saúde e relatórios de gestão. Síntese da dissertação citado por Assis, (2006). 
As restrições orçamentárias à saúde no segundo mandato do governo FHC permaneceram principalmente pela manutenção da desvinculação da Receita da União (DRU $)^{1}$ com gastos sociais para a promoção de superávit fiscal primário, e que se mantém até 2015. Concomitante a essa limitação, os recursos assegurados para a saúde com a tentativa de instituição da Emenda Constitucional n. ${ }^{0} 29$ foram cerceados pelo entendimento do critério da "base fixa" do seu artigo 77, além de contingenciamento dos recursos da saúde pelas alterações do Poder Executivo à dotação orçamentária disposta na Lei das Diretrizes Orçamentárias. Foi a partir dessa conjuntura econômica, que se sucederam fatos relevantes nas políticas de saúde bucal no segundo mandato do governo FHC.

Um estudo sobre a municipalização no Brasil demonstrou que, no período de 1993 a 1998, a ampliação da oferta própria de serviços ambulatoriais pelos gestores locais não se associava à dinâmica político-partidária, nem com as relações entre o poder executivo e legislativo municipal, mas com a operacionalização dos incentivos descentralizados pelo governo federal. (CÓRDON, 1991) Assim, no que tange à saúde bucal, apesar das limitações dos propósitos do governo (TESTA, 1992) face à implantação dos serviços e respectiva organização, a criação de um incentivo específico no final do ano de 2000, na gestão do ministro José Serra, foi um fato importante para expansão dos serviços na atenção básica da política de saúde bucal (BRASIL, 2000). Por sua vez, a oferta das ações e serviços odontológicos especializados ficou comprometida pelas dificuldades inerentes à implementação das diretrizes dispostas na NOAS, bem como pelo financiamento limitado ao repasse de recursos de acordo com produção, nesse governo FHC.

A política macroeconômica do governo FHC foi mantida e aprofundada no mandato do governo Lula, com manutenção de todos os meios de restrição orçamentária aplicados pela gestão anterior. (MENDES; MARQUES, 2005) Contudo, a implementação da política de saúde bucal nunca havia merecido tanto destaque, sugerindo, nessa nova conjuntura política, a aglutinação de forças democráticas sensíveis à saúde bucal enquanto direito de cidadania. (OPS/ OMS, 2006) Faz-se constar que o conteúdo da política Brasil Sorridente se apresentou como proposta do programa de governo do então candidato, em

\footnotetext{
Desvinculação das Receitas da União é o controle realizado pelo governo brasileiro para facilitar a manutenção de receita em relação aos gastos públicos, ou seja, 20\% das vinculações constitucionais obrigatórias de toda a arrecadação tributária brasileira não tem sido cumpridas e foi renovada até dezembro de 2015.
} 
2002, onde se propunha a continuidade dos investimentos nas ESBs na ESF, bem como a oferta de procedimentos especializados. O governo Lula chegou a 15.086 ESBs em 2006 (254,04\% de aumento em relação a 2002) e a oferta serviços especializados passou de 100 centros especializados em 2004 para 498 centros em 2006 (aumento de 398\%).

Porém, há de se considerar que a integralidade das ações e serviços especializados em saúde bucal e a própria legitimidade do Brasil Sorridente são dependentes de uma rede de ESBs resolutiva e que se organize enquanto porta de entrada do sistema, a fim de que os centros de especialidade não se constituam em atenção à livre demanda, considerando a publicidade do programa em meios de comunicação de massa naquele período inicial e consequente pressão política sobre os gestores locais.

O caráter hegemônico da prática odontológica tradicional, compreendendo hegemonia como direção moral de fração da classe odontológica dominante sobre a totalidade, associado à expansão de cursos de graduação em odontologia e mudança do perfil epidemiológico de cárie dentária com tendência à maior redução nas classes médias e altas, levou o Estado a abrir mercado direta ou indiretamente para essa mão de obra profissional excedente, sendo que este Estado prosseguiu "reduzindo-se" à condição de Estado periférico, encontrando-se submetido à interferência do cenário externo na forma de ajustes aplicados em um contexto de globalização financeira e produtiva. (ORTIZ, 1996) É, portanto, resposta seletiva do Estado já que esses ajustes basearam-se na "desregulamentação dos mercados, na abertura comercial e financeira e na privatização do setor público”. (SOARES, 2001, p. 19) Por sua vez, um dos reflexos dessa configuração de Estado na saúde, além das restrições orçamentárias impostas pela área econômica, pode ser observada na precarização das relações de trabalho. As propostas de flexibilização dos vínculos empregatícios, segundo o disposto no Plano do Ministério da Administração e Reforma do Estado (BRASIL, 1995) seriam condizentes em uma administração estatal moderna, porém, inviáveis, principalmente, ao se tratarem do setor saúde, pela capacitação específica desses profissionais. Foi nessas condições adversas que, nos governos FHC e Lula, o PSF abriu-se enquanto mercado de trabalho para os profissionais de saúde bucal. (ASSIS, 2006)

Sem desconsiderar a importância de uma remuneração satisfatória dos profissionais de saúde, é equivocada a ideia de que a garantia de salários e valorização profissional reflitam em compromisso na resolução dos problemas dos 
usuários ou em atendimento acolhedor. O modo de assistir em saúde estaria mais dependente de uma determinada concepção em saúde que considere a construção de uma nova subjetividade em cada profissional e usuário, resultando em uma relação entre sujeitos, ambos produtores de saúde. Essa mudança dependeria da própria forma como o trabalhador de saúde relaciona-se "com o seu 'objeto de trabalho', com a vida e o sofrimento dos indivíduos e da comunidade". (MERHY, 1997, p. 123)

Essa percepção de uma nova prática em saúde (bucal) esteve presente nas diversas propostas emanadas das conferências e encontros ao longo das últimas décadas, bem como nas diretrizes políticas nacionais da área. Por sua vez, aspectos favoráveis à reorientação do modelo de atenção em saúde bucal, a nível municipal, encontram-se relacionados a projetos específicos de reorganização das práticas de saúde local, à capacidade técnica dos atores envolvidos e à respectiva governabilidade para implementação.

A partir das análises realizadas, constata-se a evolução das políticas de saúde bucal formuladas e implementadas nos governos FHC e Lula, porém, podese inferir que a viabilidade a longo prazo da odontologia no SUS apresenta a mesma limitação tratada por Vianna (1988), diante do caráter secundário dessas políticas mediante questões de maior gravidade da saúde. Mesmo quando tomadas como políticas prioritárias, estão em aberto as potencialidades do seu desenvolvimento e a perspectiva incerta do seu futuro. O modelo de atenção hegemônico em odontologia contribui para o afastamento da legitimação que essas políticas poderiam alcançar junto à população, permanecendo suscetível às conjunturas governamentais.

\section{Referências}

ASSIS, L. N. Políticas de Saúde Bucal Pós-Constituinte. 2006. 118 p. Dissertação de Mestrado (Mestrado em Saúde Comunitária) - Instituto de Saúde Coletiva, Universidade Federal da Bahia, Salvador, 2006.

BRASIL. Ministério da Administração e Reforma do Estado. Plano Diretor da Reforma do Aparelho do Estado do Ministério da Administração e Reforma do Estado (MARE), 1995.

BRASIL. Ministério da Saúde. $11^{a}$ Conferência Nacional de Saúde: o Brasil falando como quer ser tratado : Relatório Final. Brasília, DF, 2002b. Disponível em: <http://conselho.saude. gov.br/biblioteca/Relatorios/relatorio_11.pdf> Acesso em: 20 out. 2005.

BRASIL, Ministério da Saúde. Diretrizes da Política de Saúde Bucal, janeiro de 2004a. Disponível em: <ttp://bvsms.saude.gov.br/bvs/publicacoes/politica_nacional_brasil_ sorridente.pdf $>$. Acesso em: 15 out. 2005. 
BRASIL,. Ministério da Saúde. Política Nacional de Humanização do SUS, 2004b. Disponível em: <http://portal.saude.gov.br/portal/saude/cidadao/area.cfm?id_area=1342> Acesso em: 13 dez. 2005 .

BRASIL. Ministério da Saúde. Portaria $\mathrm{n}^{\circ}$ 2.215, de 5 de dezembro de 2001. Redefine os critérios para a avaliação da atenção básica segundo NOAS 01/2001. Brasília, DF, 6 dez. $2001 \mathrm{a}$.

BRASIL. Ministério da Saúde. Portaria $\mathrm{n}^{0}$ 267, de 6 de março de 2001. Aprova as normas e diretrizes de inclusão da saúde bucal no PSF. Diário Oficial [da] República Federativa do Brasil, Brasília, DF, 7 mar. 2001b.

BRASIL. Ministério da Saúde. Portaria $\mathrm{n}^{\circ} .373$, de 12 de janeiro de 2002. Aprova a Norma Operacional de Assistência à Saúde NOAS-SUS 01/2002. Diário Oficial [da] República Federativa do Brasil, Brasília, DF, 28 fev. 2002.

BRASIL. Ministério da Saúde. Portaria $\mathrm{n}^{0}$ 1.444, de, 28 de dezembro de 2000. Estabelece incentivo financeiro para reorganização da atenção à saúde bucal no PSF. Diário Oficial [da] República Federativa do Brasil, Brasília, DF, 29 dez. 2000.

BRASIL. Ministério da Saúde. Portaria $\mathrm{n}^{0} 74$, de 20 de janeiro de 2004. Reajusta valores de incentivos financeiros para ações de saúde bucal no PSF e inclui procedimentos de moldagem. Diário Oficial [da] República Federativa do Brasil, Brasília, DF, 22 jan. 2004.

BRASIL. Poder Legislativo. Lei Federal n ${ }^{\circ} 3.999$, de 15 de dezembro de 1961. Altera o salário-mínimo dos médicos e cirurgiões-dentistas. Diário Oficial [da] República Federativa do Brasil, Brasília, DF, 21 dez. 1961. Disponível em: <http://www.trto2.gov.br/geral/ tribunal2/Legis/Leis/3999_61.htm>. Acesso em: 10 nov. 2005.

BRUYNE, P. et al. Dinâmica da pesquisa em ciências sociais. Rio de Janeiro: Francisco Alves, 1997.

CENTRO PANAMERICANO DE PLANIFICACIÒN DE SALUD. Formulacion de Políticas de Salud. Caracas: CENDES, 1975.

CORDÓN, J. A. Saúde bucal e a municipalização da saúde. Divulgação em Saúde para Debate, Londrina, v. 32, p. 60-65, 1991.

COUTINHO, C. N. Representação de interesses, formulação de políticas e hegemonia. In: TEIXEIRA, Fleury S. Reforma Sanitária: em busca de uma teoria. Rio de Janeiro: Editora Cortez - ABRASCO, 1995.

FERREIRA, D. O. et al. Este Aparelho de Estado Pode não ser um Aparelho qualquer. Revista Divulgação em Saúde para Debate, Londrina, v. 28, p. 48-51, 1990.

GERSCHMAN, S. Sobre formulação de políticas sociais. In: TEIXEIRA. S. F. (Org.) Reforma Sanitária:em busca de uma teoria. Rio de Janeiro: Editora Cortez; ABRASCO, 1995 .

GRAMSCI, A. Maquiavel, a política e o Estado Moderno. 4. ed. Rio de Janeiro: Civilização Brasileira. 1980. p. 48-50. 
KLECZKOWSKI, B. M.; ROEMER M.; WERFF, A.V.D. Sistemas Nacionales de Salus y su reorientación hacia la salud para todos. Pautas para uma política. Cuadernos de Salud publica, OMS, 77, 134p, 1984.

MANSUR M. C. O. Financiamento federal da saúde no Brasil: tendências da década de 1990. 2001. 119 f. Dissertação (Mestrado em Saúde Pública) - Escola Nacional de Saúde Pública, Funadação Oswaldo Cruz, Rio de Janeiro, 2001. Disponível em: http://portalteses.cict. fiocruz.br/pdf/FIOCRUZ/2001/mansurmcm/capa.pdf. Acesso em: 2 mar. 2006.

MENDES, A. N.; MARQUES, R. M. O impacto da política econômica do governo Lula na Seguridade Social e no SUS. Divulgação em Saúde para Debate, Rio de Janeiro, v. 29, n. 71, p. $258-267,2005$.

MENDES, E. V. A reforma sanitária e a educação odontológica. Caderno de Saúde Pública, Rio de Janeiro, v. 2, n. 4, dec. 1986.

MERHY, E. E. Em Busca da Qualidade dos Serviços de Saúde: Os Serviços de Porta Aberta para a Saúde e o Modelo Tecno-Assistencial em Defesa da Vida. In: CECÍLIO, L. C. O.

(Org.) Inventando a mudança na saúde. São Paulo: Editora HUCITEC, 1997, 334p.

OFFE, C. Capitalismo desorganizado. São Paulo: Brasiliense, 1989.

OPAS/OMS. A política nacional de saúde bucal no Brasil: registro de uma conquista histórica. Brasília, DF, 2006. (Séria Técnica Desenvolvimento de Sistemas de Saúde, 11).

ORTIZ, A. R. et al. A proposta da reforma do aparelho de estado e suas possíveis implicações no SUS... São Paulo: Faculdade de Saúde Pública da Universidade de São Paulo, 1996. p. 8-16. (Série Monográfica n. 5 Eixo Políticas, Planejamento e Administração).

PAIM, S. J. Modelos de Atenção e Vigilância da Saúde. In: ROUQUAYROL, M. Z; ALMEIDA FILHO, N. F. Epidemiologia e saúde, Rio de Janeiro: Editora MEDSI Ltda., 2003.

PORTATIERO, J. C. Los usos de Gramsci. México: Folios Ediciones,1983.

POULANTZAS, N. O Estado, o poder e o socialismo. Rio de Janeiro, Graal, 1980.

RONCALLI, Â. G. A organização da demanda em serviços públicos de saúde bucal:

Universalidade, equidade e integralidade em Saúde Bucal Coletiva. 2000234 f. Tese

(Doutorado em Odontologia Preventiva e Social) - Faculdade de Odontologia, Universidade Estadual Paulista Júlio de Mesquita Filho, Araçatuba, 2000.

SOARES, R. T. L. Ajuste neoliberal e desajuste social na América Latina, Petrópolis, RJ: Editoras Vozes, 2001.

TEIXEIRA, S. F. Reflexões teóricas sobre democracia e reforma sanitária. In: TEIXEIRA, S. F. Reforma Sanitária:em busca de uma teoria. Rio de Janeiro: Editora Cortez; ABRASCO, 1995.

TESTA, M. Pensar em saúde. Porto Alegre: Artes Médicas, 1992.

VIANNA, M. I. P. Estado e Atenção Odontológica no Brasil: um estudo sobre as Políticas de Saúde Bucal na conjuntura Pós-74. 211p. Tese (Mestrado em Saúde Comunitária) -, Universidade Federal da Bahia, Salvador. 1988. 